\title{
New Validated RP - HPLC Method For the Estimation of Phenanthrene in tablet Formulation
}

\author{
VD N kumar Abbaraju', V.Sreeram2 \\ E-mail ID:nagendra.git@gmail.com
}

${ }^{1}$ Department of Chemistry, GITAM University, Visakhapatnam-530 045, Andhra Pradesh, India

${ }^{2}$ Department of chemistry, A.G.\& S.G. Siddhartha College of Arts \& Science, Vuyyuru, Krishna (Dt) -521165.A.P. INDIA. 3

ABSTRACT:

A simple, selective, linear, precise and accurate RP-HPLC method was developed and validated for rapid assay of Phenanthrene in Bulk and Pharmaceutical tablet Formulation. Isocratic elution at a flow rate of 1.5 $\mathrm{ml} / \mathrm{min}$ was employed on symmetry Agilent $\mathrm{C18} 5 \mathrm{\mu m}(4.6 \mathrm{~mm} \times 15 \mathrm{~cm})$ at ambient temperature. The mobile phase consisted of Acetonitrile : Water in the ratio of 70:30/v/v. The UV detection wavelength was 254nm and $100 \mu l$ sample was injected. The retention time for Phenanthrene is $2.0 \mathrm{~min}$. The percentage RSD, Precession, Repeatability for Linearity and accuracy of the method was found.The method was validated as per the ICH guidelines. The method was successfully applied for routine quality control analysis of pharmaceutical formulation.

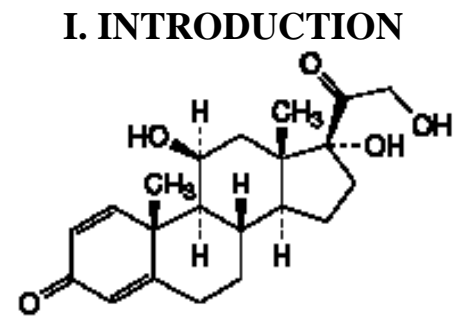

Fig: 1 Structure of Phenanthrene

The chemical formula for Phenanthrene is $\mathrm{C}_{21} \mathrm{H}_{28} \mathrm{O}_{5}$. IUPAC Name for Phenanthrene is Tricyclo[8.4.0.0 $0^{2,7}$ tetradeca-1,3,5,7,9,11,13-heptaene. A white or almost white, crystalline powder, hygroscopic,very slightly soluble in water, soluble in alcohol and in methanol, sparingly soluble in acetone, slightly soluble in methylene chloride. It shows polymorphism. The Density is $1.18 \mathrm{~g} / \mathrm{cm}^{3[1]}$. The point group is $\mathrm{C}_{2 \mathrm{v}}{ }^{[2]}$. Phenanthrene is nearly insoluble in water but is soluble in most low polarity organic solvents such as toluene, carbon tetrachloride, ether, chloroform, acetic acid and benzene. The Bardhan-Sengupta phenanthrene synthesis is a classic way to make phenanthrenes. ${ }^{[3]}$ Reactions of phenanthrene typically occur at the 9 and 10 positions, including: Organic oxidation to phenanthrene quinone with chromic acid ${ }^{[4]}$ Organic reduction to $9,10-$ dihydrophenanthrene with hydrogen gas and raney nickel ${ }^{[5]}$ Electrophilic halogenation to 9-bromophenanthrene with bromine ${ }^{[6]}$ Aromatic sulfonation to 2 and 3-phenanthrenesulfonic acids with sulfuric acid ${ }^{[7]}$ Ozonolysis to diphenylaldehyde ${ }^{[8]}$.

Mandava V. Basaveswara Rao et.al., ${ }^{[9]}$ proposed A simple, rapid and precise reverse phase high performance liquid chromatography method was developed for the analysis of Diacerein in tablet. Chromatographic separation of Diacerein was performed by using a Chromosil C18 column $(250 \times 4.6 \mathrm{~mm}, 5 \mu \mathrm{m})$ as stationary phase with a mobile phase comprising of Methanol : Water 80:20 (v/v) at a flow rate of $0.5 \mathrm{~mL}$ min-1 and UV detection wave length at $250 \mathrm{~nm}$ and $20 \mu \mathrm{L}$ sample was injected. The retention time for Diacerein was $8.29 \mathrm{~min}$. The percentage RSD for precision and accuracy of the method was found to be $0.399 \%$. Results of recovery studies are shown range $99.00-101.45 \%$. The limit of detection for Diacerein was found to be 0.06 . The recovery was calculated by standard addition method. The proposed method was found to be simple, sensitive and reproducible for the analysis of Diacerein. M. Madhava Rao ${ }^{[10]}$ et.al., developed a simple, specific, accurate, and precise RP HPLC method has been developed for the assay of Tramadol $\mathrm{HCl}$ in capsule dosage form using C18column (Hypersil BDS, $250 \times 4.6 \mathrm{~mm}, 5.0 \mu \mathrm{m})$. The sample was analyzed using 29.5 Volumes of Acetonitrile and 79.5 volumes $\mathrm{f}$ $.2 \% \mathrm{v} / \mathrm{v}$ Tri-fluroacetic acid as a mobile phase at a flow rate of $1.0 \mathrm{ml} / \mathrm{min}$ and detection at $270 \mathrm{~nm}$. The retention time for Tramadol Hydrochloride was found to be $6.327 \mathrm{~min}$. The developed method was validated for accuracy, precision, linearity, specificity, and sensitivity in accordance with ICH guidelines. Validation revealed that the method is specific, rapid, precise, reliable, and reproducible. Calibration plots were linear over the concentration ranges $6-120 \mathrm{mg} / \mathrm{ml}$. The method can be used for estimation of Tramadol Hydrochloride drug in capsules dosage form. 


\section{II.i Instrumentation}

\section{Experimental}

Peak HPLC containing LC 20AT pump and variable wavelength programmable UV-Visible detector and Rheodyne injector was employed for investigation. The chromatographic analysis was performed on a Agilent C18 $5 \mu \mathrm{m}(4.6 \mathrm{~mm} \times 15 \mathrm{~cm})$. Degassing of the mobile phase was done using a Loba ultrasonic bath sonicator. A Denwar analytical balance was used for weighing the materials.

\section{II.ii Chemicals and solvents}

The reference samples of Denorex medicated shampoo were obtained from Cipla, Mumbai. The Formulation was procured from the local market. acetonitrile and Water used were of HPLC grade and purchased from Merck Specialities Private Limited, Mumbai, India.

\section{II.iii the mobile phase}

A mixture of Acetonitrile : Water in the ratio of $70: 30 / \mathrm{v} / \mathrm{v}$ was prepared and used as mobile phase.

\section{II.iv Preparation of solutions}

Standard Solution

\section{Accurately weigh $100 \mathrm{mg}$ Phenanthrene standard into a $200 \mathrm{ml}$ volumetric flask. Dissolve and}

dilute the volume with solvent (stock solution). Dilute $5 \mathrm{ml}$ of stock solution to $100 \mathrm{ml}$ with solvent.

Dilute $2 \mathrm{ml}$ of solution with $100 \mathrm{ml}$ of solvent. Filter through $0.45 \mu \mathrm{m}$ filter, discarding the first $5 \mathrm{ml}$ of

filtrate.

\section{Sample Preparation}

Accurately weigh $500 \mathrm{mg}$ of sample into a $200 \mathrm{ml}$ volumetric flask. Dissolve and dilute to volume with solvent. Filter through $0.45 \mu \mathrm{m}$ filter, discarding the first $5 \mathrm{ml}$ of filtrate. Prepare the mobile phase and set up the equipment as specified in the standard procedure. Inject the standard and sample preparations to test the system suitability.

\section{Method Development}

For developing the method, a systematic study of the effect of various factors was undertaken by varying one parameter at a time and keeping all other conditions constant. Method development consists of selecting the appropriate wave length and choosing stationary and mobile phases. The following studies were conducted for this purpose:

\section{III.i Detection of wavelength}

The spectrum of 10ppm solution of Phenanthrene was recorded separately on UV spectrophotometer. The peak of maximum absorbance wavelength $254 \mathrm{~nm}$ was observed.

\section{III.ii Choice of stationary phase and mobile phase} equivalent

Finally the expected separation and peak shapes were obtained on Agilent C18 $5 \mu \mathrm{m}(4.6 \mathrm{~mm}$ x $15 \mathrm{~cm})$ or

\section{III.iii Flow rate}

Flow rates of the mobile phase were changed from $1.0-2.0 \mathrm{ml} / \mathrm{min}$ for optimum separation. It was found from experiments that $1.5 \mathrm{ml} / \mathrm{min}$ flow rate was ideal for elution of analyte.

\section{Validation Procedure and Requirements}

The analytical performance of the method of analysis was checked for specificity, System suitability, detection

\section{IV.i Specificity}

limit, and method precision.

Specificity of an analytical procedure is its ability to assess unequivocally the analyte in the presence of components that may be expected to be present. The solvent and placebo solutions must contain no components, which co-elute with the Phenanthrene peak. The peak purity results from the photo diode-array analysis must show that the Phenanthrene peak is pure - i.e. the purity angle (PA) must be less than the threshold angle (TH). The solutions listed below were injected using the conditions specified in the method of analysis. Prednisolone is stable under UV light exposure. No components are seen to co-elute with Phenanthrene peak, and the peak purity results indicate that Phenanthrene peak can therefore be considered spectrally pure. Chromatogram results were shown from Fig:2 to Fig:7 and peak purity results were shown from Fig:8 to Fig:11. 


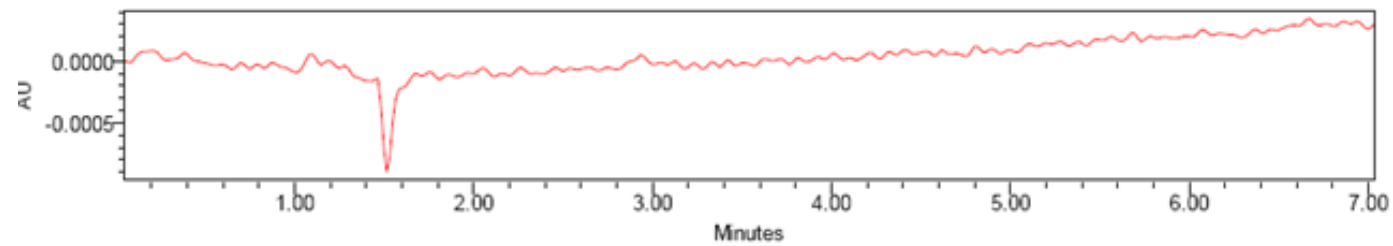

Fig: 2 Solvent - No significant peak detected

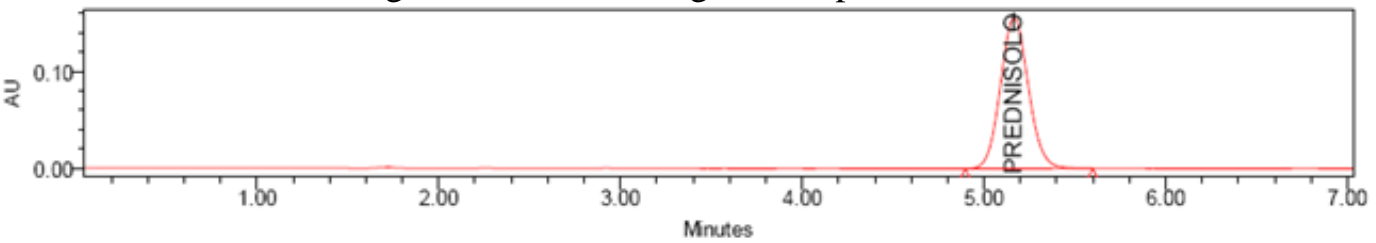

Fig: 3 Drug active - Peak due to Phenanthrene eluted at 5.1 minutes

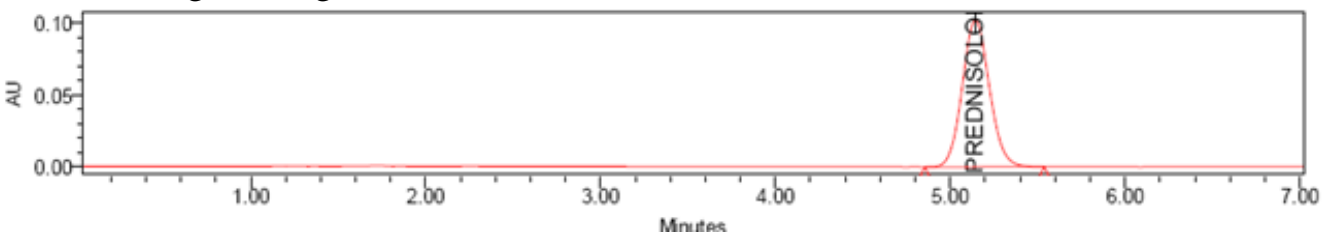

Fig: 4 Product - Peak due to Phenanthrene eluted at 5.1 minutes

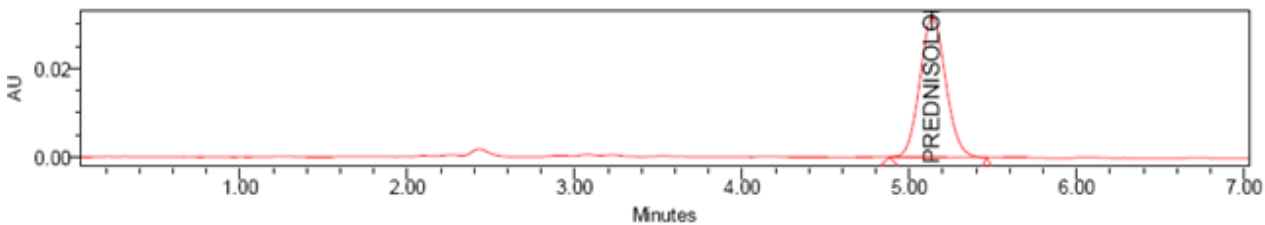

Fig: 5 Active - UV stress: Peak due to Phenanthrene eluted at 5.1 minutes

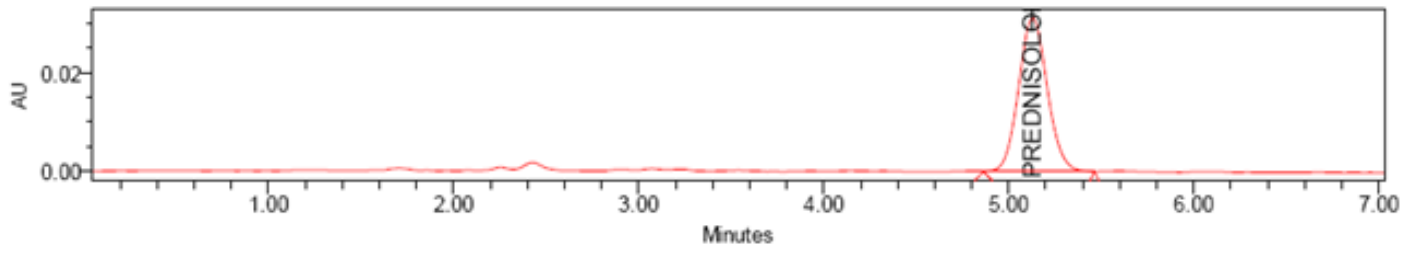

Fig: 6 Product - UV stress: Peak due to Phenanthrene eluted at 5.1 minutes

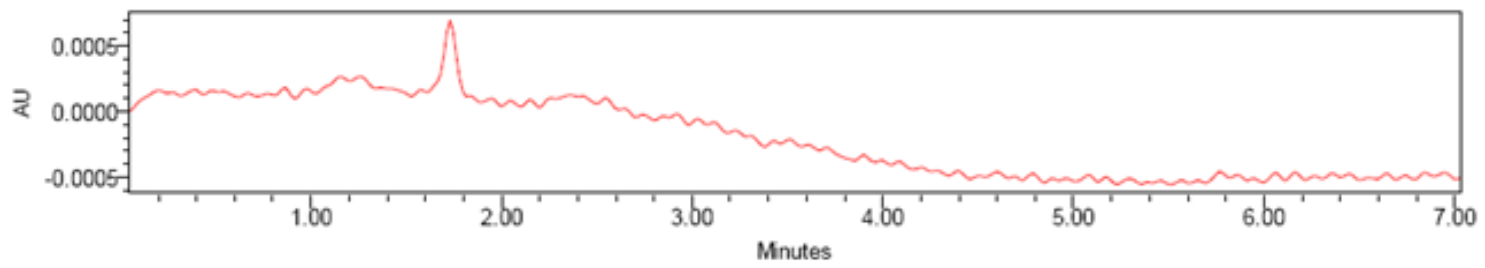

Fig: 7 Placebo - No significant peak detected

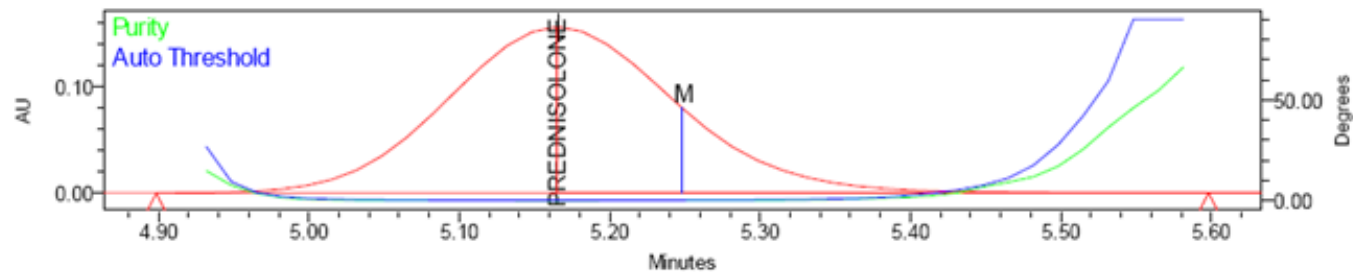

Fig: 8 Drug active Purity angle $<$ Threshold $0.096<0.283$

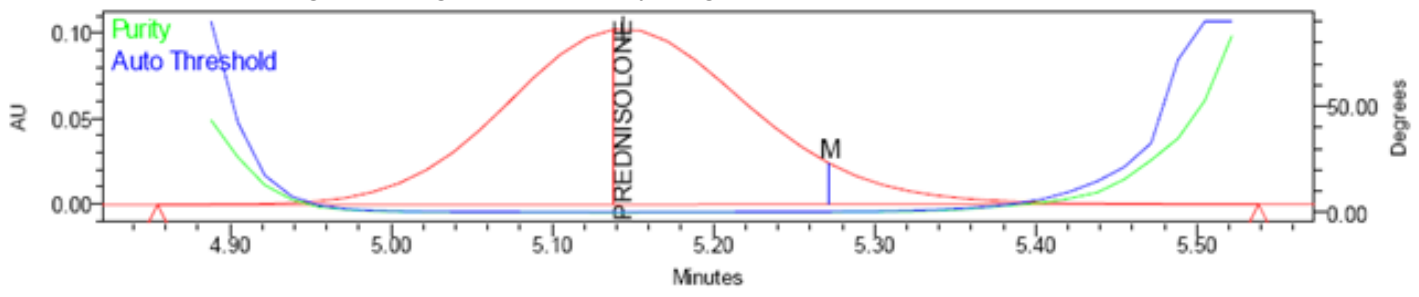

Fig: 9 Drug product Purity angle $<$ Threshold $0.126<0.314$ 


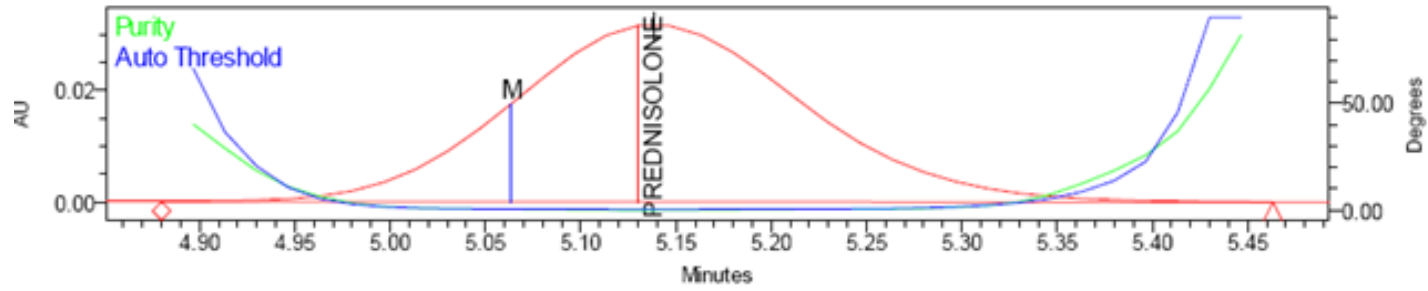

Fig: 10 Drug active Purity angle $<$ Threshold $0.456<0.504$

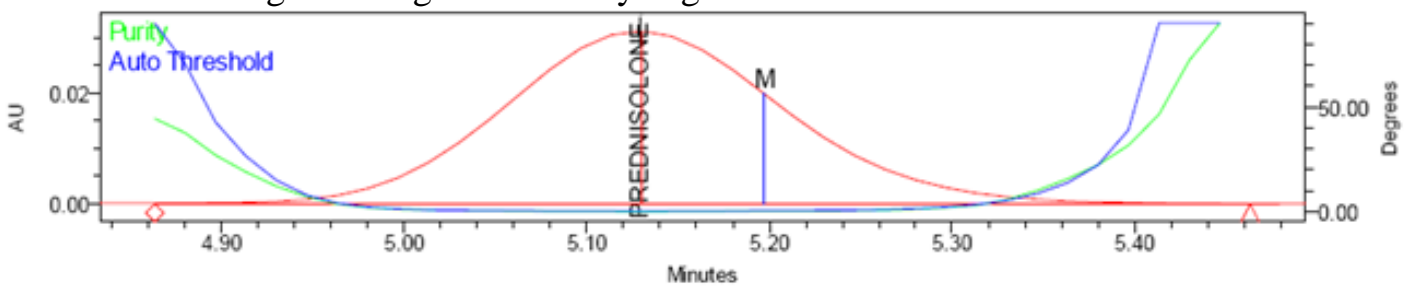

Fig: 11 Drug product Purity angle $<$ Threshold $0.458<0.576$

IV.ii System Suitability

System suitability is a measure of the performance and chromatographic quality of the total analytical system - i.e. instrument and procedure. The requirements for system suitability for this method are: The \% RSD of the peak responses due to Phenanthrene for the six replicate injections must be less than or equal to $2.0 \%$. The tailing factor of the peak due to Phenanthrene must not be more than 2.0. The theoretical plate count must not be less than 2000. Six replicate injections of working standard solution were injected according to the method of analysis. The percentage relative standard deviation (\% RSD) for the peak responses was determined. The analytical system complies with the requirements specified by the system suitability. Results are tabulated in the Table:1.

\begin{tabular}{|c|c|c|c|}
\hline Sample & Phenanthrene Area & Phenanthrene Tailing & Phenanthrene Tangent \\
\hline 1 & 97403 & 1.0 & 8727 \\
2 & 97176 & 1.0 & 8873 \\
3 & 97050 & 1.0 & 8934 \\
4 & 96965 & 1.0 & 9003 \\
5 & 96998 & 1.0 & 9067 \\
6 & 96810 & 1.0 & 9147 \\
\hline Mean & 97067 & 1.0 & 8959 \\
\hline \% RSD & 0.21 & & \\
\hline
\end{tabular}

Table: 1 Results for System suitability

IV.iii Linearity

The linearity of an assay method is its ability to elicit test results, which are directly

proportional to the concentrations of drug actives in samples in a given range. Proof of linearity justifies the use of single-point calibrations. The correlation coefficient of the regression line for Phenanthrene should be greater than or equal to 0.999. The Y-intercept of the line should not be significantly different from zero, i.e. the assessment value (z) falls within the specified limits only when $+2>z>-2$. Five solutions containing 50, 75, 100, 125, and $150 \%$ of Phenanthrene, relative to the working concentrations of $0.005030 \mathrm{mg} / \mathrm{ml}$, were prepared and injected according to the method of analysis. A linear regression curve was constructed, and the correlation coefficients $\left(\mathrm{R}^{2}\right)$ and assessment values calculated. The correlation coefficient $\left(\mathrm{R}^{2}\right)$ for Phenanthrene is 1.000 . The plot is a straight line, and the assessment value ( $\mathrm{z}$ ) is 0 for Phenanthrene. Calibration curve was shown in the Fig: 12. And Calibration Results were shown in the Table: 2.

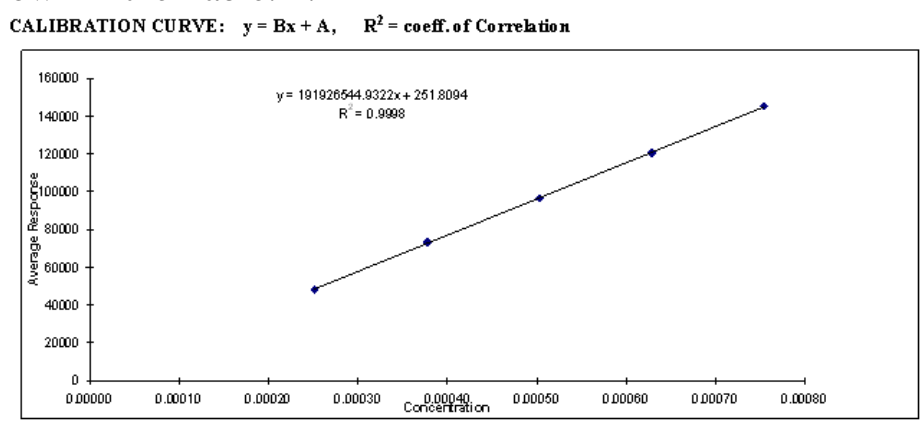

Fig: 12 Calibration curve 


\begin{tabular}{|c|c|c|c|c|}
\hline $\begin{array}{c}\text { Sample } \\
\text { Number }\end{array}$ & Concentration & Response 1 & Response 2 & Average Response \\
\hline $50 \%$ & 0.00025 & 48144 & 48212 & 48178 \\
\hline $75 \%$ & 0.00038 & 73377 & 73435 & 73406 \\
\hline $100 \%$ & 0.00050 & 96488 & 96659 & 96574 \\
\hline $125 \%$ & 0.00063 & 120640 & 120405 & 120523 \\
\hline $150 \%$ & 0.00075 & 145440 & 145147 & 145294 \\
\hline
\end{tabular}

Table: 2 Calibration Results

IV.iv Accuracy

The accuracy of an analytical method expresses the closeness of test results obtained by that method to the true value. The percentage recovery of the active compounds, for each solution prepared, must be within $98.0-102.0$ $\%$ of the actual amount. Sample solutions were spiked with known concentrations of Phenanthrene to result in concentrations of $0.0002304 \mathrm{mg} / \mathrm{ml}, 0.0003456 \mathrm{mg} / \mathrm{ml}, 0.0004608 \mathrm{mg} / \mathrm{ml}, 0.0005760 \mathrm{mg} / \mathrm{ml}$, and $0.06912 \mathrm{mg} / \mathrm{ml}$ representing respectively 50,75,100,125, and $150 \%$ of Phenanthrene relative to the working concentration of $0.0004608 \mathrm{mg} / \mathrm{ml}$. The above samples were injected in duplicate according to the method of analysis. From the accuracy results above, the percentage recovery values for Phenanthrene satisfy the acceptance criteria for accuracy across the range of $50 \%-150 \%$. Results are shown in the Table: 3 .

\begin{tabular}{|c|c|c|c|c|}
\hline Sample & Theoretical & Actual & \% Recovery & Average\% Recovery \\
\hline $50 \%$ & 0.04608 & 0.04653 & 101.0 & \multirow{2}{*}{101.2} \\
\hline $50 \%$ & 0.04608 & 0.04672 & 101.4 & \multirow{2}{*}{100.9} \\
\hline $75 \%$ & 0.06912 & 0.06977 & 100.9 & \multirow{2}{*}{99.7} \\
\hline $75 \%$ & 0.06912 & 0.06967 & 100.8 & \multirow{2}{*}{100.1} \\
\hline $100 \%$ & 0.09216 & 0.09177 & 99.6 & \\
\hline $100 \%$ & 0.09216 & 0.09190 & 99.7 & \multirow{2}{*}{99.4} \\
\hline $125 \%$ & 0.1152 & 0.1153 & 100.1 & \\
\hline $125 \%$ & 0.1152 & 0.1152 & 100.0 & \\
\hline $150 \%$ & 0.1382 & 0.1377 & 99.6 & \\
\hline $150 \%$ & 0.1382 & 0.1371 & 99.2 & \\
\hline
\end{tabular}

Table:3 Accuracy Results

IV.v Method Precision

The precision of an analytical procedure expresses the degree of agreement among individual test results when the method is applied repeatedly to multiple sampling of a homogenous sample.

\section{Repeatability}

This parameter determines the repeatability of assay results under the same operating conditions over a short period of time. The \% RSD due to Phenanthrene concentration for the six samples must be less than or equal to $2.0 \%$. Six separate sample preparations of batch 233095 were analysed according to the method of analysis. The $\%$ RSD due to Phenanthrene concentration for the assay meets the requirements for reproducibility at $1.2 \%$. The results are shown in the Table: 4. 


\begin{tabular}{|c|c|}
\hline Sample number & Results $(\mathbf{m g} / \mathbf{m l})$ \\
\cline { 2 - 2 } & Phenanthrene \\
\hline 1 & 0.1874 \\
2 & 0.1824 \\
3 & 0.1816 \\
4 & 0.1816 \\
5 & 0.1835 \\
6 & 0.1847 \\
\hline Mean & 0.1835 \\
\hline \% RSD & 1.2 \\
\hline
\end{tabular}

Table:4 Repeatability Results

\section{Intermediate Precision}

Intermediate Precision of an analytical procedure expresses intra-laboratory variations of the repeatability test performed: by a different analyst, on a different day, and using different reagents, mobile phases and solvents. The \% RSD due to Phenanthrene concentration for the six samples must be less than or equal to $2.0 \%$. The mean results obtained in the repeatability, and the intermediate precision must not differ by more than $3.0 \%$. Six separate sample preparations of batch 233095 were assayed according to the method of analysis. The \% RSD for intermediate precision is $1.3 \%$. The intermediate precision and repeatability comply as they differ by $0.2 \%$. The results are tabulated in Table:5 and Table: 6 respectively.

\begin{tabular}{|c|c|}
\hline \multirow{2}{*}{ Sample } & Results $(\mathbf{m g} / \mathbf{m l})$ \\
\cline { 2 - 2 } & Phenanthrene \\
\hline 1 & 0.1853 \\
2 & 0.1832 \\
3 & 0.1823 \\
4 & 0.1884 \\
5 & 0.1818 \\
6 & 0.1829 \\
\hline Mean & 0.1840 \\
\hline \% RSD & 1.3 \\
\hline & Table: 5\% RSD results \\
\hline
\end{tabular}

\begin{tabular}{|c|c|}
\hline \multirow{2}{*}{ Sample } & Mean Results $(\mathbf{m g} / \mathbf{m l})$ \\
\cline { 2 - 2 } & Phenanthrene \\
\hline Repeatability & 0.1835 \\
\cline { 2 - 2 } Intermediate Precision & 0.1840 \\
\hline Mean & 0.1838 \\
\hline \% RSD & 0.2 \\
\hline
\end{tabular}

Table: 6 Intermediate precision results

\section{IV.vi Range}

Range of an analytical procedure is the interval between the upper and lower concentration of analyte in the sample for which it has been demonstrated that the analytical procedure has a suitable level of precision, accuracy and linearity. Based on the accuracy results, the range for the assay of Denorex Medicated Shampoo is $2.5-7.5$ $\mathrm{mg} / \mathrm{tab}$ of Phenanthrene, which represents $50 \%$ to $150 \%$ of the working concentration.

\section{CONCLUSION}

The method for the assay of Denorex Medicated Shampoo complies with the requirements for linearity, specificity, system suitability, method precision and accuracy across the range of $50 \%$ to $150 \%$. The method is therefore acceptable as valid.

\section{REFERENCES}

1) Record of CAS RN 85-01-8 in the GESTIS Substance Database of the IFA

2) Peter Atkins, J. D. P., Atkins' Physical Chemistry. Oxford: 2010. Pg.443

3) "Bardhan Sengupta Synthesis". Comprehensive Organic Name Reactions and Reagents 49. 2010. pp. 215-219. 
doi:10.1002/9780470638859.conrr049.

4) Organic Syntheses, Coll. Vol. 4, p.757 (1963); Vol. 34, p.76 (1954)

5) Organic Syntheses, Coll. Vol. 4, p.313 (1963); Vol. 34, p.31 (1954)

6) Organic Syntheses, Coll. Vol. 3, p.134 (1955); Vol. 28, p.19 (1948)

7) Organic Syntheses, Coll. Vol. 2, p.482 (1943); Vol. 16, p.63 (1936)

8) Organic Syntheses, Coll. Vol. 5, p.489 (1973); Vol. 41, p.41 (1961)

9) Ravatite Mineral Data

10) Hoover, Rachel (February 21, 2014). "Need to Track Organic Nano-Particles Across the Universe? NASA's Got an App for That". NASA. Retrieved February 22, 2014.

11) Mandava V. Basaveswara Rao ${ }^{1 *}$, A. V. D. Nagendrakumar ${ }^{2}$ and Jogi Kusuma3; "A New Validated RP-HPLC Method For The Estimation of Diacerein In Pharmaceutical Dosage Form" Journal of Applicable Chemistry; 2014; 3 (4): 1705-1712.

12) M. Madhava Rao*,E. Gireesh Kumar,M. Madhu,A.Sushmitha; "Development and validation of RP-HPLC method for the assayof tramadol hcl in its capsule formulation”. IJAPR ; 2014; 5(7): 326-33. 